\title{
Influences of Stuck Radioactive Sources on Fire Risk of Irradiation Room
}

\author{
Xiao-Lin $\mathrm{YAO}^{1, \mathrm{a},{ }^{*}}$ \\ ${ }^{1}$ Luzhou Vocational and Technical College, Luzhou, Sichuan, 646005, China \\ afiresafety@qq.com \\ *Corresponding author
}

Keywords: Irradiation room, Radioactive sources, Stuck radioactive sources, Fire risk.

\begin{abstract}
The typical ${ }^{60} \mathrm{Co}$ irradiation room of hanging chain conveyor has been taken as a research subject. Ignition temperatures of common radiation cargo were measured through the experiment method, minimum ignition temperature is $210^{\circ} \mathrm{C}$. To get the temperature variation and temperature field under stuck radioactive sources, a fire scenario was presented and simulated by FDS. The results show that temperatures rise faster when stuck radioactive source broke out within an hour. As the growth of the time, the temperature has been on the rise, but slowly. The stuck radioactive source occurred after 11.9 days later, local temperatures can reach $210^{\circ} \mathrm{C}$, radiation cargo may be ignited..
\end{abstract}

\section{Introduction}

In recent years, the nuclear technology is widely used in food preservation, irradiation processing, and material modification [1]. With an increasing number of irradiation facilities in our country, the measurement of safety and protection could be particularly important. But if a radiation accident occurs, it will cause significant economic impact and even result in irradiation processing [2].

Stuck radioactive sources in irradiation room mean that the radioactive sources are stuck in the process of back to source well, not able to reach the design position. Cargo in irradiation room are irradiated for a long time, temperatures constant rising, it may cause a risk of fire, and than lead to a radiation accident. So we must care about the when cargo to be ignited under stuck radioactive sources. Based on the current status, FAN brought forward some safety measure combining the irradiation facilities current situation [3]. QIAO analyzed the cause of radioactivity fire, and some suggestions for the treatment were presented [4]. LI explored the main features and common reasons of radioactivity fire. The countermeasure to defend and rescue the radioactivity fire was put forward [5].

Researchers in related fields are oriented toward qualitative analysis and have little quantitative analysis on its specific methods or the results on radioactivity fire. Until recently, there is some lack of sophisticated quantitative analysis about ignition time under stuck radioactive sources. In this paper, typical ${ }^{60} \mathrm{Co}$ irradiation room of hanging chain conveyor has been taken as a research subject. The ignition temperatures of common radiation cargo in irradiation room were measured by the DW-02 ignition point detector. Considering the most disadvantage condition of the irradiation room, the fire scenario was simulated to research the fire risk by FDS. The studies looked at the ignition time of cargo in irradiation room under stuck radioactive sources through numerical simulation and experiments.

\section{Model of Irradiation Room}

\section{Irradiation Room Description.}

The purpose of this thesis is aimed to research the fire risk on typical ${ }^{60} \mathrm{Co}$ irradiation room. The room is $15 \mathrm{~m}$ long, $7 \mathrm{~m}$ wide, $4.6 \mathrm{~m}$ high as shown in Fig.1. There are three doors, one for slings in, one for slings out, and the other one for personal access, with the window closed. The room is equipped with mechanical ventilation system under normal operating conditions. The thickness of the concrete wall is $2 \mathrm{~m}$. Irradiation room transports cargo through the hanging chain conveyor. Radioactive sources are 
arranged on the shelf uniformly which is about $5 \mathrm{~m}$ long, $2 \mathrm{~m}$ high, $0.1 \mathrm{~m}$ thick, and $1 \mathrm{~mm}$ thick. $1 \mathrm{~mm}$ thick aluminum plate wrap around the shelf [6].

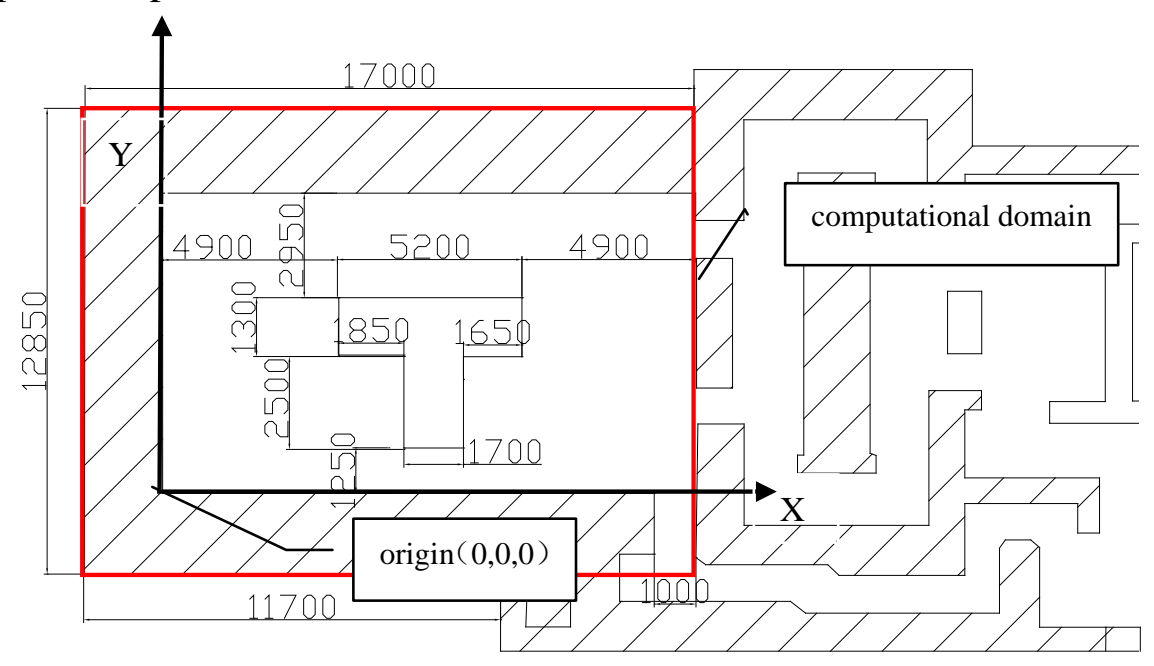

Fig. 1 The plans of the irradiation room

\section{Fire Model of Irradiation Room.}

(1) Analysis of fire risk.

Through literature, irradiation room has two major fire risks under stuck radioactive sources. One is destruction of structural member due to high temperature in the room. And the other is lead to a fire because the cargo in irradiation room is irradiated for a long time, temperatures constant rising. Through the analysis of the reference materials, concrete strength is not changed obviously while temperatures are below $300^{\circ} \mathrm{C}$ [7]. Concrete strength decreases and its external surface has cracks when temperature varies between $600 \sim 700^{\circ} \mathrm{C}$. The spalling of concrete might occur and its strength is close to zero when temperature varies between $800 \sim 900^{\circ} \mathrm{C}$. Ignition temperatures of common radiation cargo are much lower than concrete failures temperature. Therefore ignition temperatures of common radiation cargo are taken as the criterion of fire risk.

To analyze fire risk clearly under stuck radioactive sources, ignition temperatures of common radiation cargo should be determined exactly through the experiment method. Regularity of a change in temperature is obtained under typical fire scenarios through the numerical stimulation calculation, and finally arrived at the ignition time, that is the less time it will take to troubleshoot the radiation accident.

(2) Fire model.

To analyze fire risk clearly under the most disadvantage condition, this paper makes the following assumptions: 1) ${ }^{60}$ Co source releasing heat continuously is equal to the sources of heat under stuck radioactive sources. 2) The ventilation system can not work properly. 3) The irradiation room becomes a enclosed space while the exits and entrances are quickly blocked by cargo. 


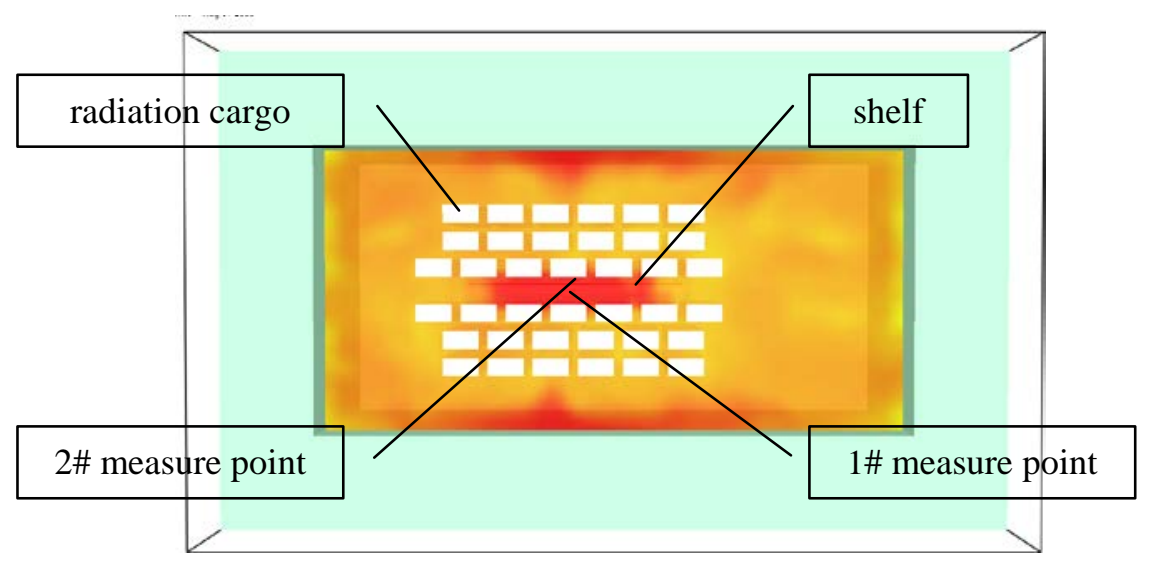

Fig.2 Model of FDS

Fire simulation software FDS widely adopted at home and abroad is used to simulation. Thermal conductivity of concrete wall is $0.72 \mathrm{w} / \mathrm{m} \bullet \mathrm{k}$. Simulation time is set to six hours because of a long time computation. Model of FDS was built as shown in Fig.2.

(3) Fire scenarios.

According to relationship between activity of ${ }^{60} \mathrm{Co}$ source and heat power, 1000Ci is roughly equivalent to $15.4 \mathrm{w}$. The activity of ${ }^{60} \mathrm{Co}$ source is $500000 \mathrm{Ci}$ and coordinates of measure points are set up as shown in table 1

Table 1. List of fire scenario

\begin{tabular}{llll}
\hline \multirow{2}{*}{ activity of ${ }^{60}$ Co source (Ci) } & heat power $(\mathrm{kW})$ & $\begin{array}{l}\text { coordinates of } \\
1 \# \quad \text { measure } \\
\text { point }\end{array}$ & $\begin{array}{l}\text { coordinates of } \\
\text { 2\# measure } \\
\text { point }\end{array}$ \\
\hline 500000 & 7.7 & $(7.5,5.3,2.0)$ & $(7.5,5.2,3.5)$ \\
\hline
\end{tabular}

According to results of linear fitting between $1 \mathrm{~h}$ and $6 \mathrm{~h}$, we can determine whether the temperatures could be ignition point and when to ignition based on the numerical simulation results. This method can calculate accurately and conservatively.

\section{Ignition Temperatures of Radiation Cargo.}

The ignition temperatures of common radiation cargo in irradiation room were measured by the DW-02 ignition point detector according to national standards GB4610-84<Test for flammability of plastics temperature test $>$, as shown in Tab. 2.

Table 2. Experimental results of ignition temperatures

\begin{tabular}{lll}
\hline radiation cargo & selected reasons & $\left.\begin{array}{l}\text { ignition } \\
\text { temperatures }(\end{array}{ }^{\circ} \mathrm{C}\right)$ \\
\hline chili powder & $\begin{array}{l}\text { ignited in the radioactivity fire in Qi } \\
\text { county of Henan province, typical food }\end{array}$ & 210 \\
\hline $\begin{array}{l}\text { corrugated } \\
\text { paper }\end{array}$ & $\begin{array}{l}\text { typical packing materials, } \\
\text { lower ignition temperature }\end{array}$ & 230 \\
\hline toilet paper & typical commodity & 240 \\
\hline gauze & typical medical supplies & 290 \\
\hline
\end{tabular}




\section{Analysis of Simulation Results}

\section{Simulation Results of Temperature Curve.}

$500000 \mathrm{Ci}$ is equivalent to $7.7 \mathrm{~kW}$ in the fire scenario. The temperature variety curve in irradiation room is drawn as shown in Fig.3.

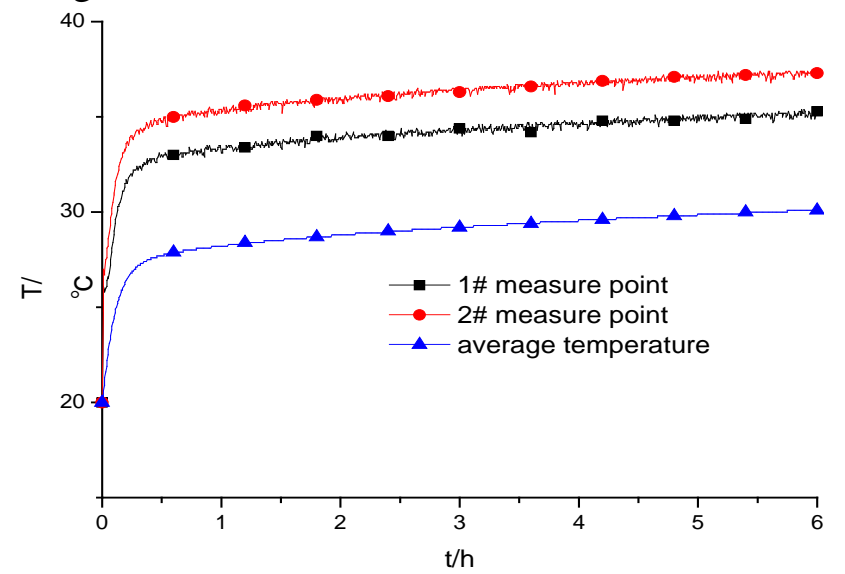

Fig.3 Temperature variety curve of every measure point

The temperatures of computational domain increase to $35.4^{\circ} \mathrm{C}$ rapidly from 0 to $1 \mathrm{~h}$. The 2 \#measure point is the largest one on account of the highest temperatures. The liner fitting formula of temperature for 2\#measure point is $T=0.61392 t+34.23007$ as shown in Fig.9. The ignition point of chili powder is $210^{\circ} \mathrm{C}$ through experiment. By analysing the simulated result of the liner fitting formula, the time to get ignition point is about 11.9 days. The radiation cargo in irradiation room may be ignited to cause a radioactivity fire.

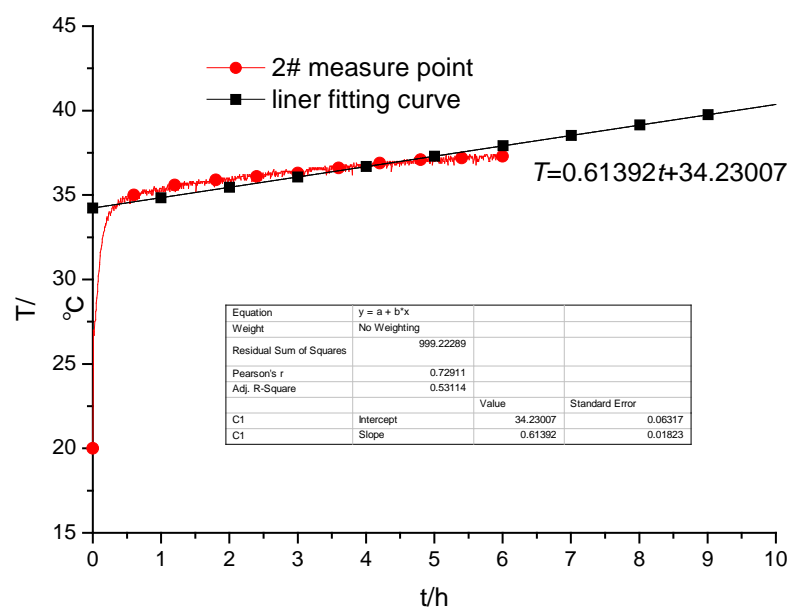

Fig.4 Liner fitting curve of temperature for 2\#measure point

\section{Conclusions}

The typical ${ }^{60} \mathrm{Co}$ irradiation room of hanging chain conveyor has been taken as a research subject in this paper. Considering the most disadvantage condition, numerical simulation and experimental methods are used to research the radioactivity fire . This paper draws the following conclusion:

(1) The radiation cargo in irradiation room has a low ignition point. The ignition temperatures of corrugated paper, chili powder, toilet paper and gauze are $230^{\circ} \mathrm{C}, 210^{\circ} \mathrm{C}, 240^{\circ} \mathrm{C}$ and $290^{\circ} \mathrm{C}$ measured by the experiment.

(2) The temperatures of computational domain increase rapidly from 0 to $1 \mathrm{~h}$. As time progresses, slower growth of temperatures is presented gradually from $1 \mathrm{~h}$ to $6 \mathrm{~h}$. The liner fitting formulas of 
temperature for $2 \#$ measure point can be obtained. The irradiation room may be caused a radioactivity fire after 11.9 days under stuck radioactive sources.

The combustibles should be taken away from the irradiation room as soon as possible once stuck radioactive source occurs. In order to decrease the temperature of irradiation room, the ventilation system could function correctly and the exits and entrances must keep clear.

\section{References}

[1] Meiyang Zheng, Guohua Jin, Genfang Shen, The radiation protection environmental assessment for 60Co irradiation room, Nuclear Electronics \& Detection Technology. 30 (2010) 1224-1226.

[2] Rongsheng Yu, Monitor in situ and personnel dose control in cobalt-60 source replenishment, Chinese Journal of Radiological Health. 10 (2001) 133-134.

[3] Xiaolin Yao, Study on fire risk assessment on round irradiation room of stacking under stuck radioactive sources , Advanced Materials Research. 919 (2014) 512-517.

[4] Shengeng Fan,Yongxian Zhang, Changheng Xu, Safe technique and experience of 60Co irradiator, Atomic Energy Science and Technology. 23 (1989) 88-93.

[5] Haitao Qiao, Hang Li, Study on fire hidden trouble and countermeasures of 60Co irradiation facilities, Annual Report For China Institute of Atomic Energy. 12 (2011) 252-254.

[6] Xiaolin Yao, Study on fire risk assessment on irradiation room under stuck radioactive sources, Advanced Materials Research. 919 (2014) 507-511.

[7] JunhaiZhao, Maohong Yu,Yunhe Liu, Yongqiang Zhang, Unified Strength Theory for Concrete and Its Application, Journal of Northwestern Institute of Architectural Engineering. 12 (1988) 1-9. 